\title{
Fertility preserving management of early endometrial cancer in a patient cohort at the department of women's health at the university of Tuebingen
}

\author{
Jürgen Andress ${ }^{1}$. Jana Pasternak ${ }^{1}$. Christina Walter ${ }^{1} \cdot$ Stefan Kommoss ${ }^{1}$ - Bernhard Krämer ${ }^{1}$. Andreas Hartkopf ${ }^{1}$. \\ Sara Yvonne Brucker ${ }^{1} \cdot$ Birgitt Schönfisch ${ }^{1}$. Sahra Steinmacher ${ }^{1}$ (I)
}

Received: 27 July 2020 / Accepted: 17 November 2020 / Published online: 19 February 2021

(c) The Author(s) 2021

\begin{abstract}
Purpose To investigate the oncologic and reproductive outcome of a conservative treatment with progestin agents in earlystage grade 1 endometrial cancer (G1EC), grade 2 endometrial cancer (G2EC) or complex atypical hyperplasia (CAH) in young premenopausal women.

Methods Women treated for early-stage endometrial cancer or atypical hyperplasia of the endometrium with a conservative therapy between 2006 and 2018 were enrolled in this retrospective analysis. Progestin agents were orally administered on a daily basis for 3 months for at least one cycle. Endometrial tissue was obtained by hysteroscopy and Dilatation \& Curettage $(D \& C)$ being performed before and after end of treatment. Therapeutic response was assessed by pathological examination. Results A total of 14 patients were included. After treatment with progestin agents, 11 of these patients initially showed a complete or partial response. Three patients with early-stage endometrial cancer did not respond.

Of the three patients with initially diagnosed atypical hyperplasia, none showed any remaining disease later. Of the eight patients with initially diagnosed endometrial cancer, who had responded to first treatment, three patients were re-diagnosed with endometrial cancer later. One patient with initial endometrial cancer became pregnant but aborted in the 10th week. Conclusion Due to its good efficacy, progestin agents offer a feasible therapeutic option in the fertility-preserving treatment of early-stage endometrial cancer in young premenopausal women. However, recurrence rate remains high. Therefore, a close follow-up is mandatory, also in responders. Patients should be informed of limitations and risks of conservative treatment. Yet after completion of family planning, hysterectomy should be performed.
\end{abstract}

Keywords Fertility sparing treatment $\cdot$ Low-grade endometrial cancer $\cdot$ Complex atypical hyperplasia $\cdot$ Progestin agents

\section{Introduction}

Endometrial cancer represents the most common entity of gynecologic cancers in Germany and the second most common worldwide. Annually, it is being diagnosed in 11.000 women in Germany and with $4.7 \%$ of all new cancer diagnoses, it ranges among the four most common cancer entities behind breast, colorectal and lung cancer (Robert-KochInstitut). Endometrial cancer typically occurs in postmenopausal women, often detected through vaginal bleeding. As

Jürgen Andress

juergen.andress@med.uni-tuebingen.de

1 Department of Women'S Health, Tuebingen University Hospital, Calwerstr. 7, 72076 Tuebingen, Germany the incidence of causing risk factors, such as diabetes, or adiposity increases in industrialized countries, it is also becoming more prevalent in younger, premenopausal women, accounting for $15-25 \%$ of all cases of endometrial cancer [1]. $10 \%$ of the patients with endometrial cancer are being diagnosed younger than 45 years, $4 \%$ are even under 40 [2].

Among women with genetic predisposition like the Lynch Syndrome, the risk for endometrial cancer rises significantly when it is simultaneously diagnosed with non-insulindependent diabetes or hypercholesterinemia [3]. Other risk factors include high blood pressure, early age at menarche and polycystic ovaries [4].

Besides the more frequent occurrences of risk factors in young reproductive woman, a notable number of them are delaying child-bearing, thus leading to an increasing number of nulliparous women being confronted with the 
diagnosis. An even larger group of women is diagnosed with complex atypical hyperplasia (CAH), the precursor lesion of endometrial cancer [5]. The established recommended surgical procedure in case of endometrial cancer consists of hysterectomy, bilateral salpingo-oophorectomy (BSO) and if necessary depending on tumor stage or histological subtype even of pelvic and paraaortic lymph node assessment (S3-Leitlinie-Endometriumkarzinom). This is commonly not an acceptable approach for women interested in future fertility in spite of the oncologic risk.

Hence, a conservative, fertility-sparing management with the use of progestin agents offers a preferred option for patients being diagnosed with $(\mathrm{CAH})$ or an early stage of endometrial cancer (G1EC) with favorable characteristics, such as the limitation to the endometrium and the good differentiation of the tumor cells. It is assumed that progestin agents induce stromal decidualization and consecutive thinning of the endometrium through activation of progesterone receptors [6].

Previous studies indicate that the progestin treatment provides a feasible option for those patients who wish to preserve fertility by providing sufficient oncologic safety at the same moment [7-10]. The conservative management does not augment the risk of progression of disease or death [11]. Today, established guidelines concerning the application of a standard protocol and treatment duration of progestin agents are still lacking due to the low number of cases. Only few studies have investigated the reproductive outcome due to the short treatment period and follow-up.

In our retrospective analysis, we evaluated the oncologic and reproductive outcome of a conservative management with progestin agents in patients with early-stage endometrial cancer or atypical complex hyperplasia in our department who were seeking a fertility-sparing treatment.

\section{Materials and methods}

Patients with complex atypical endometrial hyperplasia and/or early-stage endometrial cancer being treated conservatively for fertility preservation at the Department of Women's Health between 2006 and 2018 were included in this retrospective study.

Diagnosis was made through endometrial tissue sampling carried out by hysteroscopy and dilatation and curettage $(\mathrm{D} \& \mathrm{C})$. In the case of unclear or suspicious histological findings, a re-hysteroscopy and D\&C was performed to ensure the diagnosis. Patients were instructed to receive progestin agents orally on a daily basis for 3 months. Clinical followups to evaluate treatment success were equally performed by hysteroscopy and D\&C. The therapeutic outcome and treatment response was defined as complete response, partial response, stable disease and progressive disease.
A complete response was defined by no remaining pathological findings after clinical re-evaluation with D\&C. Partial response was considered as the change of low-grade endometrial cancer to complex atypical hyperplasia. Stable disease describes no change in histopathological findings. Progressive disease was determined as the change from complex atypical hyperplasia to low-grade endometrial cancer cells. Data extraction was performed with clinical records. The histological criteria according to WHO and to the International Federation of Gynecology and Obstetrics (FIGO) were applied. Approval by the institutional ethics committee of the Medical Faculty of the Eberhard-Karls-University was obtained (299/2017BO2).

Baseline characteristics were described by median, range, mean and standard deviation (SD), respectively, frequencies and proportions. Time to first relapse after last successful treatment was estimated by Kaplan-Meier method. Basic statistics were done by excel version 16.27 , for graphics and PFS the software R, version 3.5.1, was used.

\section{Results}

\section{Patient's characteristics}

Of all 15 patients treated in our department between 2006 and 2018, one patient was excluded due to loss of followup. Of the 14 patients included, one patient had been diagnosed with endometrial cancer grading G2 (7\%), 10 (71\%) had been diagnosed with G1EC, 3 patients (21\%) with CAH. The median age of the patients was 32.2 years (range 30.1-47.9 years) at time of diagnosis, with a mean age of 34.2 years (SD 4.8 years). The median body mass index (BMI) was $32.8 \mathrm{~kg} / \mathrm{m}^{2}$ (range $21.6-47.9 \mathrm{~kg} / \mathrm{m}^{2}$ ), the mean BMI was $33.1 \mathrm{~kg} / \mathrm{m}^{2}\left(\mathrm{SD} 8.5 \mathrm{~kg} / \mathrm{m}^{2}\right)$. Eight patients had a BMI higher than $30 \mathrm{~kg} / \mathrm{m}^{2}$ (Table 1).

Of all 14 patients, $10(71 \%)$ presented with primary infertility, 4 (29\%) patients demanded diagnostics due to secondary infertility. Out of the four patients with secondary infertility, two women have had a caesarian section before, one has had an ectopic pregnancy and one had previously delivered vaginally.

\section{Treatment}

The conservative management consisted of the oral application of $500 \mathrm{mg}$ MPA (Medroxyprogesterone acetate), $160 \mathrm{mg}$ MA (Megestrol acetate) or $10 \mathrm{mg}$ Dydrogesteron on a daily basis for 3 months. Eight patients (57\%) received MPA, whereas in five patients (35\%), MA was administered. One patient (7\%) was treated with $10 \mathrm{mg}$ Dydrogesteron. The mean duration of treatment was 4.3 months. The majority of patients received progestin 
Table 1 Baseline characteristics of the 14 patients diagnosed with endometrial cancer or atypical hyperplasia

\begin{tabular}{|c|c|c|}
\hline \multicolumn{3}{|l|}{ Initial diagnosis $n(\%)$} \\
\hline Atypical hyperplasia & 3 & $(21 \%)$ \\
\hline Endometrial cancer, G1 & 10 & $(71 \%)$ \\
\hline Endometrial cancer, G2 & 1 & $(7 \%)$ \\
\hline Age at diagnosis (years) median (range) & 32.2 & $(30.1-47.9)$ \\
\hline Body mass index $\left(\mathrm{kg} / \mathrm{m}^{2}\right)$ median (range) & 32.8 & $(21.6-47.9)$ \\
\hline \multicolumn{3}{|l|}{ Body mass index $\left(\mathrm{kg} / \mathrm{m}^{2}\right) n(\%)$} \\
\hline$<24.9 \mathrm{~kg} / \mathrm{m}^{2}$ & 3 & $(21 \%)$ \\
\hline $25-29.9 \mathrm{~kg} / \mathrm{m}^{2}$ & 3 & $(21 \%)$ \\
\hline $30-34.9 \mathrm{~kg} / \mathrm{m}^{2}$ & 2 & $(14 \%)$ \\
\hline $35-39.9 \mathrm{~kg} / \mathrm{m}^{2}$ & 2 & $(14 \%)$ \\
\hline$\geq 40 \mathrm{~kg} / \mathrm{m}^{2}$ & 4 & $(29 \%)$ \\
\hline \multicolumn{3}{|l|}{ Other risk factors $n(\%)$} \\
\hline PCOS & 2 & $(14 \%)$ \\
\hline Diabetes mellitus type II & 3 & $(21 \%)$ \\
\hline \multicolumn{3}{|l|}{ Reason for initial diagnosis $n(\%)$} \\
\hline Primary infertility & 10 & $(71 \%)$ \\
\hline Secondary infertility & 4 & $(29 \%)$ \\
\hline Ectopic pregnancy & 1 & \\
\hline Caesarian section & 2 & \\
\hline Vaginal delivery & 1 & \\
\hline \multicolumn{3}{|l|}{ Pelvic imaging $n(\%)$} \\
\hline Pelvic ultrasound & 14 & $(100 \%)$ \\
\hline MRI & 10 & $(71 \%)$ \\
\hline \multicolumn{3}{|l|}{ Progestin therapy $n(\%)$} \\
\hline MPA 500 mg/day & 8 & $(57 \%)$ \\
\hline MA 160 mg/day & 4 & $(29 \%)$ \\
\hline MA $320 \mathrm{mg} /$ day & 1 & $(7 \%)$ \\
\hline Dydrogesteron $10 \mathrm{mg} /$ day & 1 & $(7 \%)$ \\
\hline
\end{tabular}

PCOS Polycystic ovarian syndrome, MPA Medroxyprogesterone acetate, $M A$ Megestrol acetate, MRI Magnetic resonance imaging

agents for at least 3 months. One patient received for MPA $500 \mathrm{mg}$ for only 1.5 month. Treatment was terminated earlier due to side effects (Table 2).

One patient with a BMI of $42.7 \mathrm{~kg} / \mathrm{m}^{2}$ was treated with MPA $500 \mathrm{mg}$ for 10 months in total, another patient with a BMI of $47.9 \mathrm{~kg} / \mathrm{m}^{2}$ with MA $160 \mathrm{mg}$ for 12 months in total, both belonging to those three patients with the highest BMI of the cohort. The patient diagnosed with G2EC (BMI $42.8 \mathrm{~kg} / \mathrm{m}^{2}$ ) was treated with $10 \mathrm{mg}$ Dydrogesteron for 3 months in total.

Of the ten patients suffering from G1EC, six patients were treated with $500 \mathrm{mg}$ MPA between 1.5 and 10 months in total. Three patients were treated with $160 \mathrm{mg} \mathrm{MA}$, thereof one for 2.5 months, one for three months, one patient for 12 months in total. One patient was treated with $320 \mathrm{mg}$ MA for 3 months. Of the three patients diagnosed with complex atypical hyperplasia, one (BMI $23.4 \mathrm{~kg} / \mathrm{m}^{2}$ ) received $160 \mathrm{mg}$ MA for 7 months in total, two were treated with MPA $500 \mathrm{mg}$ for 3 months.

The histological follow-up, based on endometrial tissue samples obtained by hysteroscopy and D\&C was performed shortly after treatment, only in one case, the clinical control was performed 5 months after end of treatment, due to non-compliance of the patient. Controlhysteroscopies and D\&C were usually performed regularly every three months after end of therapy to ensure treatment success. If no histopathological treatment success could be found, a new treatment cycle was initiated.

\section{Outcome}

\section{Outcome after first treatment cycle}

\section{Treatment with MA}

In total, four patients of the cohort were treated with MA $160 \mathrm{mg}$. Three had been diagnosed with G1EC, one patient with CAH. One patient with a G1EC was administered MA $320 \mathrm{mg}$. After the first cycle of conservative management in the group of three patients with low-grade endometrial carcinoma, who had been treated with $160 \mathrm{mg}$ MA, one patient showed a partial response with remaining $\mathrm{CAH}$. One patient showed complete response.

One patient did not respond to treatment. In the patient treated with $320 \mathrm{mg} \mathrm{MA}$, a partial response with remaining CAH could be seen. The patient with the initial diagnosis of atypical hyperplasia and MA treatment showed a complete remission after the first cycle of treatment (see Fig. 1).

\section{Treatment with MPA}

Eight patients were treated with $500 \mathrm{mg}$ MPA, thereof six with low-grade endometrial cancer, two with atypical hyperplasia. Three patients with endometrial carcinoma had a complete response with no remaining disease after one cycle of treatment of three months. Two patients showed partial remission with remaining atypical hyperplasia. One of those had been treated for only one month, as treatment had been finished earlier due to side effects.

One patient did not respond to MPA therapy and showed remaining cancer cells. This patient underwent surgical treatment with total hysterectomy and BSO. The two patients with initially diagnosed CAH showed a complete response after one cycle of treatment. 
Table 2 Management according to initial diagnosis, age, BMI and treatment duration

\begin{tabular}{|c|c|c|c|c|c|c|c|c|}
\hline Patient ID & Diagnosis & $\begin{array}{l}\text { Age at } \\
\text { diagnosis } \\
\text { (years) }\end{array}$ & BMI $\left(\mathrm{kg} / \mathrm{m}^{2}\right)$ & Therapy (mg) & $\begin{array}{l}\text { Treatment } \\
\text { duration } \\
\text { (months) }\end{array}$ & $\begin{array}{l}\text { Follow-up } \\
\text { time (months) }\end{array}$ & $\begin{array}{l}\text { Outcome after } \\
\text { first treatment }\end{array}$ & $\begin{array}{l}\text { Outcome after last } \\
\text { treatment }\end{array}$ \\
\hline 1 & G2EC & 35.9 & 42.8 & $\begin{array}{l}\text { Dydrogesteron } \\
10\end{array}$ & & 5 & SD & l \\
\hline 2 & G1EC & 30.7 & 47.9 & MA 160 & $3+3+3+3$ & 33 & PR & SD \\
\hline 3 & G1EC & 37.0 & 21.6 & MPA 500 & $3+3$ & 18 & $\mathrm{CR}$ & PR \\
\hline 4 & G1EC & 30.4 & 38.6 & MPA 500 & 3 & 5 & SD & I \\
\hline 5 & G1EC & 31.4 & 42.7 & MPA 500 & $6+4$ & 40 & PR & $\mathrm{CR}$ \\
\hline 6 & G1EC & 30.2 & 40.8 & MPA 500 & 3 & 10 & $\mathrm{CR}$ & / \\
\hline 7 & G1EC & 32.9 & 26.7 & MA 160 & 3 & 5 & SD & l \\
\hline 8 & G1EC & 35.6 & 32.2 & MA 320 & 3 & 6 & PR & l \\
\hline 9 & G1EC & 36.6 & 26.9 & MPA 500 & 3 & 4 & CR & l \\
\hline 10 & G1EC & 47.9 & 33.5 & MPA 500 & 1.5 & 6 & PR & l \\
\hline 11 & G1EC & 30.6 & 28.5 & MA 160 & 2.5 & 40 & CR & l \\
\hline 12 & CAH & 31.6 & 36.7 & MPA 500 & 3 & 7 & CR & l \\
\hline 13 & $\mathrm{CAH}$ & 30.1 & 23.4 & MA 160 & $4+3$ & 46 & $\mathrm{CR}$ & $\mathrm{CR}$ \\
\hline 14 & CAH & 37.4 & 22.2 & MPA 500 & 3 & 11 & CR & I \\
\hline
\end{tabular}

G2EC Endometrial cancer grade 2, G1EC Endometrial cancer grade 1, CAH Complex atypical hyperplasia, $S D$ stable disease, $P R$ partial remission, $C R$ complete remission

\section{Treatment with Dydrogesteron}

One patient diagnosed with G2EC received Dydrogesteron $10 \mathrm{mg}$ for 3 months but did not respond.

\section{Outcome after various treatment cycles}

Four patients were treated for more than one cycle with progestin agents. One patient with G1EC (ID 2) was treated with four cycles of MA $160 \mathrm{mg}$ in total. After the first cycle, partial remission with remaining complex atypical hyperplasia was obtained. The patient then was treated with a second cycle with MA. In the following D\&C, a complete remission was diagnosed. Yet in the following control D\&Cs, the patient relapsed with treatment control revealed, still remaining complex atypical hyperplasia. Thus, the patient received a fourth cycle of MA. After treatment, complete remission was seen. In the subsequent curettage 8 months after end of the last treatment, the patient was re-diagnosed with endometrial cancer.

Another patient with G1EC (ID 3) showed complete remission after 3 months of treatment with $500 \mathrm{mg}$ MPA. She then relapsed with $\mathrm{CAH}$, so another treatment cycle with $500 \mathrm{mg}$ MPA was administered. The control D\&C performed directly after the end of the second treatment cycle revealed remaining $\mathrm{CAH}$. In the control hysteroscopy and D\&C after 3 months, complete remission could be diagnosed again.

A third patient with G1EC (ID 5) was treated with MPA $500 \mathrm{mg}$ for two cycles. During the first treatment cycle, complete remission could be seen. In the control D\&C, the patient relapsed with complex atypical hyperplasia. Hence, a second treatment cycle was started. In the first histopathological control, after the second treatment cycle, no pathology was found. The following curettage again revealed complex atypical hyperplasia. The patient then had two control D\&Cs, both with no pathological findings.

One patient initially diagnosed with CAH (ID 13) also received two cycles of treatment with MA $160 \mathrm{mg}$. After the first treatment cycle, complete remission was diagnosed. Yet the patient relapsed with $\mathrm{CAH}$ and was treated with another cycle of MA. In the control D\&C, complete remission was again diagnosed (see Fig. 1).

For the nine patients with response to therapy, median duration to first progression after last successful treatment was 7.8 months.

Of all 14 patients, one patient with initial endometrial cancer became pregnant but aborted in the 10th week.

\section{Discussion}

In this retrospective study, we analyzed the outcome of 14 patients with $\mathrm{CAH}, \mathrm{G} 1 \mathrm{EC}$ and G2EC being treated by different progestin agents. A treatment response after the first therapy cycle could be noticed in 11 patients, three with low-grade complex atypical hyperplasia, and eight with endometrial cancer. Yet, in three of these eight patients, the endometrial cancer was re-diagnosed after conservative progestin therapy. At the end of follow-up, two patients with 
Fig. 1 Individual treatment course of each patient demonstrates the individual treatment course of each patient with progestine agents

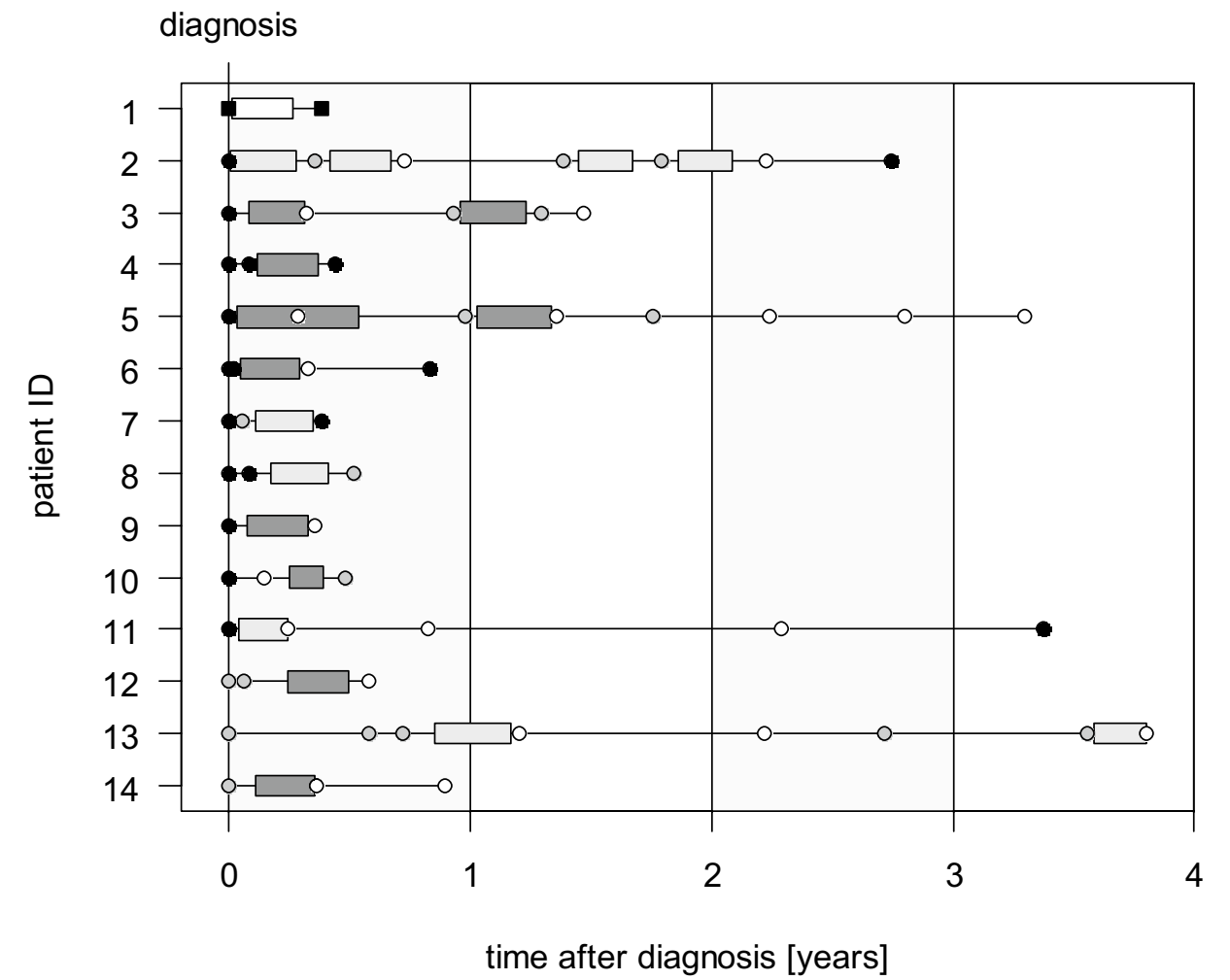

treatment

MPA

MA

Dydrogesteron

curettage

- endometrium carcinoma G2

- endometrium carcinoma G1

- atypical hyperplasia

○ non pathological an initially diagnosed endometrial cancer showed atypical endometrial hyperplasia. Unfortunately, none of our patients achieved a successful pregnancy, which was the primary goal of the conservative treatment regime. One patient with initial endometrial cancer became pregnant but aborted in the 10th week. The results highlight both, the success and limitations of the treatment with progestin agents in young women wanting to retain future fertility potential.

Until today, standardized therapy regimen concerning the fertility-preserving treatment of endometrial neoplasia is lacking. Numerous previous investigations have shown the effects of progestin agents in the fertility-preserving treatment of young patients with complex atypical hyperplasia or low-grade G1EC, whereas fertility-sparing treatment options in Stage IA and G2EC have been investigated only by few studies $[12,13]$. According to Thipgen et al., the response rate of progestin agents varies between $37 \%$ for $\mathrm{G} 1,23 \%$ for $\mathrm{G} 2$ and $9 \%$ for $\mathrm{G} 3$, assuming that grading is one of the most influential parameters in the outcome after progestin therapy [14].

Ohyagi-Hara et al. treated 27 patients with 400-600 mg MPA daily and demonstrated an initial complete response of $81 \%$ in patients with $\mathrm{CAH}$ and of $69 \%$ in patients treated for G1EC. None of the patients with $\mathrm{CAH}$ recurred, however, $81 \%$ of the patients with G1EC [15]. In a cohort of 59 patients, Fujiwara et al. reported an initial complete response of $71 \%$ in patients with G1EC after treatment with MPA, $52 \%$ of the patients relapsed over time [16]. In accordance to the systematic review of Gunderson et al., we also noted higher recurrence rates in patients with endometrial 
carcinoma [6] than in those with complex atypical hyperplasia [6]. This emphasizes the need for an immediate start of fertility treatment after achieving complete remission.

All patients of our study initially presented due to infertility problems, the uterine neoplasia was diagnosed accidently. Considering one of the primary goals of the treatment, the fertility preservation, it remains questionable whether the delay of a therapy with sufficient oncologic safety is justified by the doubtful perspective of a successful pregnancy in our cohort. This therapeutic dilemma is even underlined by the fact that the standard surgical procedure of total hysterectomy and BSO has a very good prognosis in premenopausal women [17].

To date, defined therapeutic regimens and application methods, as well as data concerning dosage and duration of progestin treatment are lacking. New approaches to establish more effective treatment regimen have been performed recently. In a systematic review, Gallos et al. demonstrated that Levenorgestrel-IUD (LNG-IUD) had a higher regression rate in atypical hyperplasia than the use of oral progestins. This therapeutic advantage did not apply for G1EC [18]. Kim et al. evaluated the therapeutic effect of a combination of oral progestins and LNG-IUD in 16 patients with G1EC. Here, $87 \%$ of all patients had an initial complete response. Of those, $14 \%$ recurred. This might suggest that a combination of both can be more effective than an oral application. The use of additional parameters that may predict treatment success can also be helpful to evaluate an individual therapeutic regimen.

In recent studies, potential molecular markers for the prediction of the possibility of achieving complete remission in early-stage endometrial cancer have been identified. Yamazawa et. al demonstrated that the positive expression of progesterone receptor was related to the rate of complete remission of low-grade endometrial cancer after MPA therapy [19]. Yet, therapy with progestin agents has proven to be effective in the treatment of hormone-negative tumors, suggesting there might be another effect of progestin on tumor cells than through the mediation of hormonal receptors [20]. The expression of the cell adhesion molecule L1-CAM in the presence of an endometrial carcinoma stage 1 may also give additional information regarding the tumor biology and prognosis. Kommoss et al. recently reported that an overexpression of L1CAM is associated with a more aggressive tumor entity and potential distant metastasis in the event of recurrence [21]. This marker might play an influential role in the future treatment algorithm of early-stage endometrial carcinoma.

The results of our study have to be interpreted in the light of some limitations. First, the study is of retrospective nature at a single institution and reveals a small sample size. Moreover, different progestin agents were used and no defined treatment duration was applied. This is due to the individualized treatment course of each patient, as therapeutic success was frequently evaluated and changes in therapy were applied.

\section{Conclusion}

Progestin agents are an effective treatment option in young patients with complex atypical hyperplasia or early-stage endometrial cancer who desire fertility-preserving therapy. Even after sufficient success of conservative therapy close clinical follow-up is mandatory and surgical procedure should be performed with no delay. Patients should be informed about limitations and possible risks of a conservative treatment compared to a definite surgical procedure. Fertility treatment should be taken into consideration after complete remission of CAH or early-stage endometrial cancer, as risk factors that favour the occurrence of endometrial neoplasia on the one hand and reduce fertility on the other hand are often prevalent in this patient group.

Hence, prospective studies with a greater study population and the identification of factors that allow a prediction of the therapeutical response to progestins are highly demanded to establish a reliable and individualized therapeutic regimen.

Author contributions JA, JP, BS, SS: substantial contributions to conception and design, acquisition of data, analysis and interpretation of data; MW: revising the article critically for important intellectual content; CW, SK, BK, AH, SYB: final approval of the version to be published.

Funding Open Access funding enabled and organized by Projekt DEAL.

Data availability Available upon request.

\section{Compliance with ethical standards}

Conflict of interest The authors declare that they have no conflict of interest.

Ethical approval This article does not contain any studies with human participants or animals performed by any of the authors.

Open Access This article is licensed under a Creative Commons Attribution 4.0 International License, which permits use, sharing, adaptation, distribution and reproduction in any medium or format, as long as you give appropriate credit to the original author(s) and the source, provide a link to the Creative Commons licence, and indicate if changes were made. The images or other third party material in this article are included in the article's Creative Commons licence, unless indicated otherwise in a credit line to the material. If material is not included in the article's Creative Commons licence and your intended use is not permitted by statutory regulation or exceeds the permitted use, you will 
need to obtain permission directly from the copyright holder. To view a copy of this licence, visit http://creativecommons.org/licenses/by/4.0/.

\section{References}

1. Gallup DG, Stock RJ (1984) Adenocarcinoma of the endometrium in women 40 years of age or younger. Obstet Gynecol 64:417-420

2. Kalogera E, Dowdy SC, Bakkum-Gamez JN (2014) Preserving fertility in young patients with endometrial cancer: current perspectives. Int J Womens Health 6:691-701

3. Staff S, Aaltonen M, Huhtala H, Pylvanainen K, Mecklin JP, Maenpaa J (2016) Endometrial cancer risk factors among Lynch syndrome women: a retrospective cohort study. Br J Cancer 115:375-381

4. Barry JA, Azizia MM, Hardiman PJ (2014) Risk of endometrial, ovarian and breast cancer in women with polycystic ovary syndrome: a systematic review and meta-analysis. Hum Reprod Update 20:748-758

5. Pecorelli S (2009) Revised FIGO staging for carcinoma of the vulva, cervix, and endometrium. Int J Gynaecol Obstet 105:103-104

6. Gunderson CC, Fader AN, Carson KA, Bristow RE (2012) Oncologic and reproductive outcomes with progestin therapy in women with endometrial hyperplasia and grade 1 adenocarcinoma: a systematic review. Gynecol Oncol 125:477-482

7. Navarria I, Usel M, Rapiti E, Neyroud-Caspar I, Pelte MF, Bouchardy C et al (2009) Young patients with endometrial cancer: how many could be eligible for fertility-sparing treatment? Gynecol Oncol 114:448-451

8. Silverberg SG, Makowski EL, Roche WD (1977) Endometrial carcinoma in women under 40 years of age: comparison of cases in oral contraceptive users and non-users. Cancer 39:592-598

9. Crissman JD, Azoury RS, Barnes AE, Schellhas HF (1981) Endometrial carcinoma in women 40 years of age or younger. Obstet Gynecol 57:699-704

10. Park JY, Seong SJ, Kim TJ, Kim JW, Kim SM, Bae DS et al (2013) Pregnancy outcomes after fertility-sparing management in young women with early endometrial cancer. Obstet Gynecol 121:136-142

11. Tangjitgamol S, Manusirivithaya S, Hanprasertpong J (2009) Fertility-sparing in endometrial cancer. Gynecol Obstet Invest 67:250-268

12. Kaku T, Yoshikawa H, Tsuda H, Sakamoto A, Fukunaga M, Kuwabara Y et al (2001) Conservative therapy for adenocarcinoma and atypical endometrial hyperplasia of the endometrium in young women: central pathologic review and treatment outcome. Cancer Lett 167:39-48
13. Rossetti D, Bogani G, Carnelli M, Vitale SG, Grosso G, Frigerio L (2014) Efficacy of IVF following conservative management of endometrial cancer. Gynecol Endocrinol 30:280-281

14. Thigpen JT, Brady MF, Alvarez RD, Adelson MD, Homesley HD, Manetta A et al (1999) Oral medroxyprogesterone acetate in the treatment of advanced or recurrent endometrial carcinoma: a doseresponse study by the Gynecologic Oncology Group. J Clin Oncol 17:1736-1744

15. Ohyagi-Hara C, Sawada K, Aki I, Mabuchi S, Kobayashi E, Ueda $Y$ et al (2015) Efficacies and pregnant outcomes of fertility-sparing treatment with medroxyprogesterone acetate for endometrioid adenocarcinoma and complex atypical hyperplasia: our experience and a review of the literature. Arch Gynecol Obstet 291:151-157

16. Fujiwara H, Jobo T, Takei Y, Saga Y, Imai M, Arai T et al (2012) Fertility-sparing treatment using medroxyprogesterone acetate for endometrial carcinoma. Oncol Lett 3:1002-1006

17. Creasman WT, Soper JT, McCarty KS Jr, McCarty KS Sr, Hinshaw W, Clarke-Pearson DL (1985) Influence of cytoplasmic steroid receptor content on prognosis of early stage endometrial carcinoma. Am J Obstet Gynecol 151:922-932

18. Montz FJ, Bristow RE, Bovicelli A, Tomacruz R, Kurman RJ (2002) Intrauterine progesterone treatment of early endometrial cancer. Am J Obstet Gynecol 186:651-657

19. Yamazawa K, Hirai M, Fujito A, Nishi H, Terauchi F, Ishikura $\mathrm{H}$ et al (2007) Fertility-preserving treatment with progestin, and pathological criteria to predict responses, in young women with endometrial cancer. Hum Reprod 22:1953-1958

20. Minaguchi T, Nakagawa S, Takazawa Y, Nei T, Horie K, Fujiwara $\mathrm{T}$ et al (2007) Combined phospho-Akt and PTEN expressions associated with post-treatment hysterectomy after conservative progestin therapy in complex atypical hyperplasia and stage Ia, G1 adenocarcinoma of the endometrium. Cancer Lett 248:112-122

21. Kommoss F, Kommoss F, Grevenkamp F, Bunz AK, Taran FA, Fend F et al (2017) L1CAM: amending the "low-risk" category in endometrial carcinoma. J Cancer Res Clin Oncol 143:255-262

Publisher's Note Springer Nature remains neutral with regard to jurisdictional claims in published maps and institutional affiliations. 